\title{
Yeasts as Biopharmaceutical Production Platforms
}

\author{
Natalja Kulagina ${ }^{1}$, Sébastien Besseau ${ }^{1}$, Charlotte Godon ${ }^{2}$, Gustavo H. Goldman ${ }^{3 *}$, \\ Nicolas Papon ${ }^{2 *}$ and Vincent Courdavault ${ }^{\text {* }}$ \\ ${ }^{1}$ Université de Tours, EA2106 Biomolécules et Biotechnologies Végétales, Tours, France, ${ }^{2}$ Université d'Angers, EA3142 \\ Groupe d'Etude des Interactions Hôte-Pathogène, Angers, France, ${ }^{3}$ Departamento de Ciências Farmacêuticas, Faculdade \\ de Ciências Farmacêuticas de Ribeirão Preto, Universidade de São Paulo, Ribeirão Preto, Brazil
}

Keywords: yeast, biopharmaceuticals, natural products, heterologous production, metabolic engineering

\section{INTRODUCTION}

Biopharmaceuticals and medicinal natural products (NPs) embrace a vast and continuously expanding range of applications in human medicine, which requires high-scale production to meet clinical demands and prevent natural source-related restraints. The development of genetic engineering tools and genome sequencing enabled the emergence of heterologous production as an alternative supply strategy. One of the pioneering examples is Escherichia coli-produced insulin, which was Food and Drug Administration (FDA)-approved and commercialized in 1982, followed by the E. coli-produced growth hormone (GH) in 1985 (Wang et al., 2017). Currently, apart from gonadotropic hormones, which are produced only in mammalian cells given their specific glycosylation (Orvieto and Seifer, 2016), most of the other commercialized hormones are synthesized by recombinant Saccharomyces cerevisiae (insulin, glucagon, GH) or E.coli [insulin, GH, glucagon, calcitonin, teriparatide (Walsh, 2018)]. Over the past decades, the constantly broadening biopharmaceutical industry exhibited the blossom of vaccines, therapeutic monoclonal antibodies (mAbs), recombinant enzymes, cytokines and blood-related proteins, most of which are produced in mammalian cells (predominantly Chinese hamster ovary cells, $\mathrm{CHO}$ ) (Walsh, 2010, 2018), a time-consuming, laborious and expensive process. Microbe expression system-derived recombinant proteins, on the other hand, face several limitations, such as post-translational modifications (PTMs), potential immunogenicity, poor stability and short serum half-life. One of the preferred heterologous expression systems are generally recognized as safe (GRAS) yeasts (e.g. S. cerevisiae, Pichia pastoris, Yarrowia lipolytica, Hansenula polymorpha), which are robust, easy to genetically manipulate, cost-effective, and unlike E. coli possess native PTM machinery and lack endotoxins (Demain and Vaishnav, 2009; Martínez et al., 2012). Still, yeast glycosylation differs from human N- and O- glycosylation, and to circumvent this limitation a major effort was directed toward yeast glycoengineering. In addition, yeast secretory machinery and endogenous protein degradation were targeted to enhance recombinant protein-folding, secretion and stability (Laukens et al., 2015; Huang et al., 2018). On the other hand, whole yeast-based vaccines (WYVs) emerged as an appealing approach to combat infectious diseases and cancers (Roohvand et al., 2017), further placing yeast in the spotlight. In parallel, the industrial-scale heterologous production of mammal- and plant-derived medicinal NPs was achieved for progesterone (Duport et al., 1998), hydrocortisone (Szczebara et al., 2003) and artemisinic acid (a precursor of antimalarial artemisinin, Paddon et al., 2013), via the complete pathway reconstitution in engineered $S$. cerevisiae. This strategy was applied to other plant-derived active compounds, such as resveratrol (800 mg/L, Li et al., 2016), 
strictosidine (0.5 mg/L, Brown et al., 2015), thebaine (0.006 $\mathrm{mg} / \mathrm{L}$, Galanie et al., 2015), ginsenoside $\mathrm{Rh} 2$ (300 mg/L, Zhuang et al., 2017) and noscapine (2.2 mg/L, Li et al., 2018). However, obtaining industry-compatible yields remains challenging due to plant pathway complexity and subcellular architecture, as well as heterologous enzyme poor activity and limiting native metabolism. In this opinion article, we will overview the main classes of recombinant biopharmaceuticals currently commercialized, and highlight the recent progress in the construction and optimization of yeast cell factories for the production of biopharmaceuticals and medicinal NPs.

\section{RECOMBINANT THERAPEUTIC PROTEINS}

\section{Vaccines}

Since their first massive application in the 1960s, vaccines have considerably improved public health and remarkably reduced child mortality (Pollard and Bijker, 2021). However, besides the time inefficiency of conventional vaccine production, which is particularly problematic concerning the newly emerging diseases, mass cultivation of pathogens displays a high risk of pathogenicity while live attenuated pathogen-based vaccines are incompatible with immunocompromised individuals (Kumar and Kumar, 2019). Thus, protein-based vaccines, virus-like particle (VLP)-based vaccines, and more recently peptide-, viral vector- and nucleic acid-based vaccines have been explored to expand and facilitate vaccine design and production (Kim and Kim, 2017; Ho et al., 2021; Pollard and Bijker, 2021). Subunitbased and VLP-based vaccines employ recombinant strategies and heterologous production in microbial cell factories, and particularly yeast platforms (Mohsen et al., 2017; Roohvand et al., 2017). For instance, recombinant vaccines produced by yeasts have been approved and employed since 1980s, notably the vaccines against hepatitis B virus (HBV) from 1986, and combination vaccines against several pathogens from 1996 (Table 1). WYV strategy, on the other hand, was inspired by adjuvant, anti-cancer and immunomodulatory properties of yeast cell wall $\beta$-glucans, which, combined with the ease of yeast genetic manipulation, gave an idea to recombinant WYVs expressing pathogen- or tumor-specific antigens on the cell surface (Roohvand et al., 2017). In S. cerevisiae, antigen anchoring to the cell surface is achieved via the fusion with cell wall proteins, such as glycosylphosphatidylinositol (GPI) and protein with internal repeats (PIR) proteins. PIR proteins are directly linked to the cell wall $\beta$-glucans while GPI proteins require specific GPI anchors (Ecker et al., 2006; Pittet and Conzelmann, 2006). While the commercialized GPI $\alpha$-agglutinin system is the most widely used, other GPI systems have been developing to improve cell surface display by assessing different GPI anchors (Yang et al., 2019). Currently, several heat-killed WYVs for oral administration are under clinical or preclinical investigation, targeting various cancers, such as melanoma, papilloma, leukemia and carcinoma (Roohvand et al., 2017; Kumar and Kumar, 2019), and viruses, including influenza H7N9 (Lei et al., 2020) and COVID-19 (Gao et al., 2021).

\section{Monoclonal Antibodies}

In parallel, therapeutic monoclonal antibodies (mAbs) and targeted immunotherapy emerged as an extensively growing class of medication aimed to treat various human pathologies, such as cancers, cardiovascular, infectious, inflammatory and autoimmune diseases (Kaplon and Reichert, 2019). Following the first murine $\mathrm{mAb}$ approved and commercialized in 1986 to prevent kidney transplant rejection, more than $100 \mathrm{mAbs}$ were developed (Walsh, 2018). The success of this approach relies on $\mathrm{mAb}$ target specificity mediated by antigen binding domain and its variable regions, and crystallizable fragment domain engaged in $\mathrm{mAb}$ function, recycling and higher serum half-life (Buss et al., 2012). In addition, mAb immunogenicity was considerably limited with the development of chimeric (65\% human, e.g., neuroblastoma-treating dinutuximab beta in 2017), humanized (95\% human, e.g., breast and gastric cancertreating trastuzumab in 2018) and human (e.g., Merkel cell carcinoma-treating avelumab in 2017) mAbs (Buss et al., 2012; Walsh, 2018). However, the specific glycosylation required for the immune response activation, as well as protein-folding issues, have been restricting mAbs production to mammalian cells (Jung and Kim, 2017). Indeed, yeast $N$ glycosylation patterns are of a high mannose type, which is immunogenic and reduces recombinant protein serum half-life in mammals. To overcome this limitation, yeast glycoengineering was engaged to prevent hypermannosylation and humanize glycosylation machinery. For instance, the deletion of $\mathrm{OCH} 1$ gene encoding the mannosyltransferase involved in the outer chain elongation of $N$-linked oligosaccharides, and the expression of heterologous $\alpha-1,2$-mannosidase resulted in the production of humanmannose type glycans, while the introduction of mammal glycosyltransferases downstream enabled the production of more complex human-type glycans (reviewed in Laukens et al., 2015). Meanwhile, $P$. pastoris emerged as a more attractive expression host given its less extensive hypermannosylation compared to $S$. cerevisiae. Subsequently, several studies demonstrated glycoengineered $P$. pastoris as a platform for the production of humanized mAbs (Bobrowicz et al., 2004; Li et al., 2006; Potgieter et al., 2009).

\section{Blood Factors and Blood-Related Proteins}

The majority of blood factors (e.g., clotting factor VIII; coagulation factors VIIa, IX, Xa, IIa, thrombolytic reteplase) are produced in mammalian cells, except several examples of yeast platforms, such as clotting fibrin stabilizing factor XIIIa expressed in $S$. cerevisiae, which treats congenital factor XIIIa deficiency and is commercialized since 2012, as well as P. pastorissynthesized clotting plasma kallikrein inhibitor and proteolytic recombinant plasmin approved in 2009 and 2012, respectively (Martínez et al., 2012; Korte, 2014; Walsh, 2018) (Table 1). Another anticoagulant is $S$. cerevisiae-produced hirudin from Hirudo medicinalis approved in 1997, which was discontinued in 2012, probably due to the risk of overdosing, only manageable by hemofiltration, and several cases of anaphylaxis (Greinacher et al., 2003; Cardenas and Deitcher, 2005; Petros, 2008; Walsh, 2018). Alternative anticoagulants have been explored, such as human antithrombin III that lyses thrombin and factor $\mathrm{Xa}$ 
TABLE 1 | FDA-approved biopharmaceuticals produced in yeast cells (adapted from Walsh, 2018).

\begin{tabular}{|c|c|c|c|}
\hline Biopharmaceutical & Expression system & First product & Target \\
\hline \multicolumn{4}{|l|}{ Hormones } \\
\hline Insulin (rh) & S. cerevisiae & $\begin{array}{l}1991 \\
\text { (Novolin 1991-2010) }\end{array}$ & Diabetes mellitus \\
\hline Glucagon (rh) & S. cerevisiae & 1999 (Glucagen) & Hypoglycemia \\
\hline Somatropin (rhGH) & S. cerevisiae & $\begin{array}{l}2006 \\
\text { (Valtropin 2006-2012) }\end{array}$ & Growth failure \\
\hline \multicolumn{4}{|l|}{ Vaccines } \\
\hline HBsAg (r) & S. cerevisiae & 1986 (Recombivax) & Hepatitis B \\
\hline Combination vaccine $(r)$ & S. cerevisiae & $\begin{array}{l}1996 \\
\text { (Tritanrix-hepB 1996-2014) }\end{array}$ & Multiple \\
\hline HPV capsid proteins $(r)$ & S. cerevisiae & 2006 (Gardasil) & $\begin{array}{l}\text { Human papillomavirus (HPX, } \\
4 \text { types) }\end{array}$ \\
\hline HBsAg (r) & H. polymorpha & 2017 (HEPLISAV-B) & Hepatitis B \\
\hline \multicolumn{4}{|l|}{ Blood-related } \\
\hline \multicolumn{4}{|l|}{ Anticoagulants } \\
\hline Hirudin (desirudin) (r) & S. cerevisiae & $\begin{array}{l}1997 \\
\text { (Revasc 1997-2014) }\end{array}$ & $\begin{array}{l}\text { Venous thrombosis, } \\
\text { thrombocytopenia }\end{array}$ \\
\hline \multicolumn{4}{|l|}{ Clotting factors } \\
\hline $\begin{array}{l}\text { Plasma kallikrein inhibitor } \\
\text { (ecallantide) (rh) }\end{array}$ & P. pastoris & 2009 (Kalbitor) & Hereditary angioedema \\
\hline $\begin{array}{l}\text { Factor XIII A-subunit } \\
\text { (catridecog) (rh) }\end{array}$ & S. cerevisiae & 2012 (Novothirteen) & $\begin{array}{l}\text { Congenital factor XIII } \\
\text { A-subunit deficiency }\end{array}$ \\
\hline \multicolumn{4}{|l|}{ Proteolytics } \\
\hline
\end{tabular}

r, recombinant; $r$, recombinant human.

upon blood coagulation cascade, and is manufactured in the milk of transgenic goats since 2006. More recently, it was reported to be expressed in $S$. cerevisiae yielding $312 \mathrm{mg} / \mathrm{L}$ in fed-batch fermentation (Mallu et al., 2016). Recombinant plasma albumin, on the other hand, has been produced in multiple expression systems, including $S$. cerevisiae and $P$. pastoris, which showed the most promising titer of above $3 \mathrm{~g} / \mathrm{L}$ and $10 \mathrm{~g} / \mathrm{L}$ in fed-batch cultivation, respectively (Chen et al., 2013). In parallel, the development of blood substitutes for transfusions, notably recombinant hemoglobin $(\mathrm{Hb})$, has been investigated for decades. Several studies displayed promising results in $S$. cerevisiae targeting the native heme biosynthesis by overexpressing HEM genes (particularly HEM3), and the optimization of recombinant $\mathrm{Hb}$ subunit $\alpha$ and $\beta$ expression via 2:1 gene copy ratio (Liu et al., 2014; Martínez et al., 2015). In addition, the deletion of HAP1 gene that encodes heme-activated transcription factor, known to initiate the transcription of respiration-related genes under high heme concentration, was shown to improve $\mathrm{Hb}$ recombinant titer up to around $7 \%$ of the total yeast protein (Martínez et al., 2015). Recently, recombinant $\mathrm{Hb}$ yield was reported to reach $18 \%$ relative to the total cellular proteins, due to the deletion of HMX1, VPS10 and PEP4 involved in heme and mis-folded protein degradation, the overexpression of AHSP encoding human $\alpha$-hemoglobin-stabilizing protein, and the deletion of ROX1 encoding heme-dependent repressor that inhibits HEM13 (Ishchuk et al., 2021).

\section{Cytokines and Growth Factors}

Pro-inflammatory (type I) and anti-inflammatory (type II) therapeutic cytokines, such as interferons (IFNs), type I tumor necrosis factors (TNFs) and interleukins (ILs) are known to display a spectrum of activities, including immunomodulatory, antiviral and antiproliferative (e.g., IFN- $\alpha$ treats hepatitis A, B, C and some types of cancer; IFN- $\beta$-multiple 
sclerosis; TNF- $\alpha$ and ILs are employed in anticancer-related therapies) (Lipiäinen et al., 2015; Walsh, 2018; Berraondo et al., 2019). Although recombinant cytokines approved for clinical use are predominantly produced in E.coli, several studies were performed to exploit yeasts as expression hosts. For example, the deletion of native lipid regulator gene OPI1 leads to the endoplasmic reticulum (ER) enlargement and enhanced secretion capacity, which is further emphasized by the overexpression of CPR5 folding factor and improved protein-folding (de Ruijter et al., 2016). In parallel, to obtain IFN- $\alpha$ 2b in Y. lipolytica (Gasmi et al., 2011) and IL-6 in P. pastoris (Li et al., 2011), fed-batch cultivation of recombinant protein-expressing strains and purification process were assessed demonstrating recombinant protein high yield and biological activity. Hematopoietic growth factor cytokines, on the other hand, comprise colony-stimulating factors (CSF) including granulocyte colony-stimulating factor (G-CSF) and granulocytemacrophage colony-stimulating factor (GM-CSF), which are employed as immunostimulants to treat neutropenia (Metcalf, 2010) and are produced since 1991 in E. coli (CSF filgrastim) and S. cerevisiae (GM-CSF sargramostim) (Table 1).

\section{Enzymes}

Several deficient enzyme disorders (e.g., mucopolysaccharidosis, Pompe disease, Fabry disease, Gaucher disease) and cancers (e.g., lymphoblastic leukemia, melanoma) can be treated by enzyme replacement therapies (Taipa et al., 2019). The majority of the approved recombinant enzymes are produced in $\mathrm{CHO}$ cells ( $\beta$-glucorebrosidase for Gaucher disease, $\alpha$-galactosidase for Fabry disease, $\alpha$-mannosidosidase for $\alpha$-mannosidosis, sulfatases for mucopolysaccharidosis, $\alpha$-glucosidase for Pompe disease, digestive enzymes), some in E. coli (E. coli urate oxidase to treat Gout and asparaginase for lymphoblastic leukemia), and $S$. cerevisiae (S. cerevisiae urate oxidase for the treatment of hyperuricemia) (Walsh, 2018; Taipa et al., 2019) (Table 1). Nevertheless, the employment of recombinant enzymes remains challenging due to their large size, potential immunogenicity, undesirable side activity, and poor stability. However, the enhancement of enzyme efficiency minimizes the required enzyme concentration, which can be achieved via site-directed mutagenesis/truncation and computational protein design (Yang et al., 2017). Another limiting factor is recombinant enzyme delivery, and several strategies have been investigated to provide a longer serum half-life and targeted distribution in vivo, such as fusion proteins, encapsulation (e.g., lysosomes, nanoparticles) and PEGylation (poly[ethylene glycol] attachment), which remain challenging and case-specific (Dean et al., 2016).

\section{THERAPEUTIC NATURAL PRODUCTS}

The extensive exploitation of natural resources and prevailing unavailability of chemical synthesis results in recurrent shortages of medicinal NPs, and particularly highly valued plant-derived compounds, such as Apocynaceae monoterpene indole alkaloids (MIAs), opium poppy benzylisoquinoline alkaloids (BIAs) and hemp cannabinoids (Cragg and Newman, 2013; Courdavault et al., 2020). Numerous of these compounds, or their precursors, have been biosynthesized in yeast (Table 2), but commonly the titer does not reach industrial scale and requires further improvement. Recently, BIA central intermediate $(S)$-reticuline yielded $4.6 \mathrm{~g} / \mathrm{L}$ (a spectacular 57,000-fold increase) in engineered S. cerevisiae, where eight heterologous enzymes were expressed and the native metabolism was modified to improve the formation and accumulation of 4-hydroxyphenylacetaldehyde (4-HPAA) (Pyne et al., 2020). However, the truncation-optimized norcoclaurine synthase (tNCS) that condensates 4-HPAA and dopamine to form the main precursor norcoclaurine showed cytotoxicity, which was further minimized by targeting tNCS to the peroxisome (Grewal et al., 2021). In parallel, the identification of missing enzymes of the tropane alkaloid (TA) pathway allowed the construction of $S$. cerevisiae strain producing scopolamine $(0.03 \mathrm{mg} / \mathrm{L})$ via a combinatorial approach. In addition to the introduction of 15 heterologous and two engineered heterologous enzymes, native arginine and polyamine metabolism were optimized to improve the accumulation of TA precursor putrescine, and endogenous intermediate degradation was addressed (Srinivasan and Smolke, 2019, 2020). On the other hand, de novo biosynthesis of highly valuable cannabinoids was reported in S. cerevisiae, where nine heterologous genes in tandem with the enhanced native mevalonate pathway and increased geranyl pyrophosphate (GPP) flux resulted in $8 \mathrm{mg} / \mathrm{L}$ of tetrahydrocannabinolic acid production (THCA) (Luo et al., 2019). Moreover, another study demonstrated that targeting the entire GPP biosynthetic pathway into peroxisomes minimizes the endogenous competition for GPP and increases up to 125fold the production of downstream GPP-derived heterologous compounds (Dusséaux et al., 2020). This displays a potential application for further improvement of cannabinoid titer given that Cannabis sativa olivetolate geranyltransferase CsPT4, which uses GPP as a co-substrate, is active in the peroxisome. Remarkably, heterologous enzyme promiscuity was assessed in several studies (Srinivasan and Smolke, 2019; Pyne et al., 2020) demonstrating the discovery of new-to-nature compounds with potentially novel biological properties, which is a prodigious feature for drug discovery.

\section{FUTURE PERSPECTIVES AND CHALLENGES}

E. coli and yeasts display several advantages compared to cell cultures and transgenic plants/animals in the context of their rapid, cost-effective and easy cultivation, as well as the ease of genomic manipulation. However, given $E$. coli endotoxins and inclusion bodies, as well as the lack of PTM system (discussed in more detail in Tripathi and Shrivastava, 2019), the yeast expression system is frequently emphasized. Thus, although yeast glycosylation differs from human glycosylation, and recombinant protein overexpression may result in insufficient secretion, the development of synthetic biology tools enabled to start addressing these issues (reviewed in Laukens et al., 2015 and Huang et al., 2018). Whereas still challenging, the humanization of yeast glycosylation and improvement of the secretory machinery unveiled the way 
TABLE 2 | Plant-derived therapeutic NPs produced in S. cerevisiae (adapted and updated from Pyne et al., 2019).

\begin{tabular}{|c|c|c|c|c|}
\hline Compound & Plant origin & Characteristic(s) & Titer (mg/L) & Reference \\
\hline \multicolumn{5}{|l|}{ Alkaloids } \\
\hline \multicolumn{5}{|l|}{$\mathrm{MIA}$} \\
\hline Strictosidine & Catharanthus roseus & Precursor of anticancer MIAs & 0.5 & Brown et al. (2015) \\
\hline \multicolumn{5}{|l|}{$\mathrm{BIA}$} \\
\hline Thebaine; & Papaver somniferum & Precursor of therapeutic opioids; & 0.006 & Galanie et al. (2015) \\
\hline Hydrocodone & & Analgesic & 0.0003 & \\
\hline Noscapine & Papaver somniferum & Antitussive & 2.2 & Li et al. (2018) \\
\hline (S)-reticuline & Papaver somniferum & Precursor of therapeutic opioids & 4,600 & Pyne et al. (2020) \\
\hline \multicolumn{5}{|l|}{ TA } \\
\hline Scopolamine & $\begin{array}{l}\text { Datura stramonium } \\
\text { Atropa belladonna }\end{array}$ & Neuromuscular disorder treatment & 0.03 & $\begin{array}{l}\text { Srinivasan and } \\
\text { Smolke (2020) }\end{array}$ \\
\hline \multicolumn{5}{|l|}{ Cannabinoids } \\
\hline $\begin{array}{l}\text { THCA; } \\
\text { CBGA; } \\
\text { CBDA }\end{array}$ & Cannabis sativa & $\begin{array}{l}\text { Psychoactive THC; } \\
\text { Psychoactive CBG; } \\
\text { Psychoactive CBD }\end{array}$ & $\begin{array}{c}8 \\
136 \\
0.004\end{array}$ & Luo et al. (2019) \\
\hline \multicolumn{5}{|l|}{ Terpenoids } \\
\hline \multicolumn{5}{|l|}{ Sesquiterpenoids } \\
\hline a-humulene; & Zingiber zerumbet & Anti-inflammatory and & 1,300 & Zhang et al. (2018) \\
\hline Zerumbone & & anticancer & 40 & \\
\hline Amorphadiene & Artemisia annua & Precursor of antimalarial artemisinin & 37,000 & Westfall et al. (2012) \\
\hline Artemisinic acid & Artemisia annua & Precursor of antimalarial artemisinin & 25,000 & Paddon et al. (2013) \\
\hline \multicolumn{5}{|l|}{ Diterpenoids } \\
\hline Jolkinol C & $\begin{array}{l}\text { Euphorbiaceae } \\
\text { Thymelaceae }\end{array}$ & Precursor of therapeutic diterpenoids & 800 & Wong et al. (2018) \\
\hline Taxadiene & Taxus brevifolia & Precursor of anticancer paclitaxel & 129 & Nowrouzi et al. (2020) \\
\hline \multicolumn{5}{|l|}{ Triterpenoids } \\
\hline$\beta$-amyrin & Wide distribution & Precursor of therapeutic triterpenoids & 279 & Liu et al. (2019) \\
\hline Ginsenoside Rh2 & Panax & Anticancer & 300 & Zhuang et al. (2017) \\
\hline \multicolumn{5}{|l|}{ Phenylpropanoids } \\
\hline \multicolumn{5}{|l|}{ Stilbenoids } \\
\hline $\begin{array}{l}\text { Resveratrol; } \\
\text { Pinostilbene; } \\
\text { Pterostilben }\end{array}$ & Wide distribution & Wide range of beneficial properties & $\begin{array}{c}800 \\
5.52 \\
34.93\end{array}$ & Li et al. (2016) \\
\hline \multicolumn{5}{|l|}{ Flavonoids } \\
\hline Naringenin & Wide distribution & Wide range of beneficial properties & $>200$ & Lehka et al. (2017) \\
\hline Scutellarin & Erigeron breviscapis & $\begin{array}{l}\text { Cardio/cerebrovascular disease } \\
\text { treatment }\end{array}$ & 108 & Liu et al. (2018) \\
\hline Genistein & Genista tinctoria & Phytoestrogen, angiogenesis inhibitor & 7.7 & Trantas et al. (2009) \\
\hline Pinocembrin; & Wide distribution & Antioxidant, antidiabetic; & 2.6 & $\begin{array}{l}\text { Eichenberger et al. } \\
\text { (2017) }\end{array}$ \\
\hline Phloretin & Wide distribution & Precursor of hypoglycemic phlorizin & 42.7 & Rodriguez et al. \\
\hline Quercetin & & Wide range of beneficial properties & 20.38 & $(2017)$ \\
\hline Kaempferol & Wide distribution & Wide range of beneficial properties & 66.29 & Duan et al. (2017) \\
\hline
\end{tabular}

toward heterologous production of, in principle, any therapeutic recombinant protein, including mAbs (Figure 1A). Moreover, WYVs and yeast potential for the production of recombinant hemoglobin-based oxygen carriers and meat substitutes further spotlight yeast as an auspicious production platform (Lei et al., 2020; Gao et al., 2021; Ishchuk et al., 2021). On the other hand, high-scale heterologous production of therapeutic
NPs, particularly plant-derived metabolites, encounters a more extensive range of obstacles due to the complexity of plant metabolic pathways (Figure 1B). Indeed, multi-enzyme pathway subcellular compartmentalization, enzyme promiscuity and poor activity, intermediate cytotoxicity and competing native metabolism require combinatorial strategies. In addition to pathway elucidation, the development and advances of synthetic 

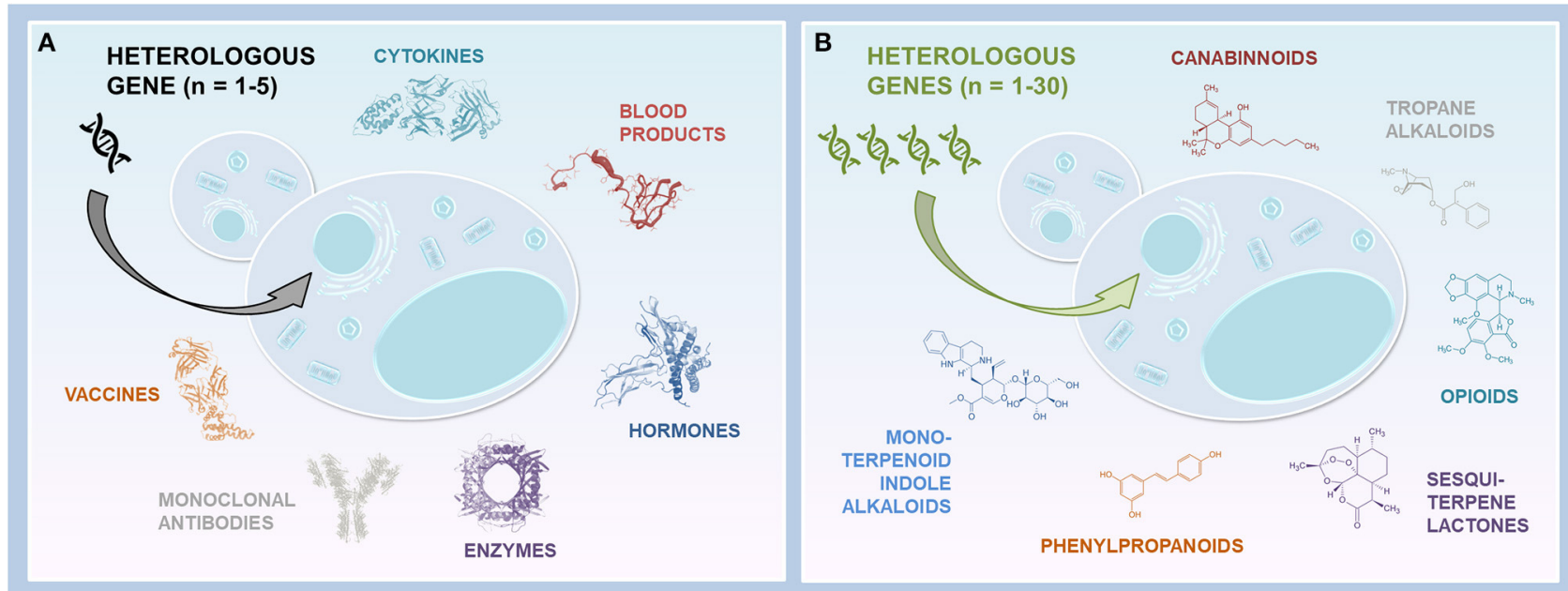

FIGURE 1 | Yeast platforms expressing heterologous genes. (A) Yeast cells producing biopharmaceuticals. Few heterologous genes are required to produce recombinant proteins of interest. In some cases, several genes are necessary (e.g., multiple gene copies, fusion proteins, Hb, glycosylation humanization). (B) Yeast cells producing NPs. Multiple heterologous genes are introduced into yeast to reconstitute the entire metabolic pathways and produce the compounds of interest, or their precursors.

biology tools, including CRISPR/Cas9 system, fine-tuning of gene expression and enzyme activity, rewiring primary metabolism for cofactor or substrate supply, as well as exploiting subcellular localization (Guirimand et al., 2020), enabled the rise of heterologous pathway reconstitution in yeast. For instance, the optimization of native metabolism is frequently employed to revise metabolic fluxes (Luo et al., 2019; Dusséaux et al., 2020; Pyne et al., 2020; Srinivasan and Smolke, 2020), and enzyme(s) relocalization to the peroxisome appeared as a promising strategy to increase yields (Dusséaux et al., 2020; Grewal et al., 2021). In parallel, with the expanding large highquality datasets, predictive engineering and systems metabolic engineering emerged as a tool to facilitate the design of desired cell properties via specific genetic modifications (Lee et al., 2012; Zhang et al., 2020). Thus, further implementation of computation and rational strategies in addition to pathway characterization, as well as current and future progress in metabolic engineering, promise a prominent potential of yeast

\section{REFERENCES}

Berraondo, P., Sanmamed, M. F., Ochoa, M. C., Etxeberria, I., Aznar, M. A., PérezGracia, J. L., et al. (2019). Cytokines in clinical cancer immunotherapy. Br. J. Cancer 120, 6-15. doi: 10.1038/s41416-018-0328-y

Bobrowicz, P., Davidson, R. C., Li, H., Potgieter, T. I., Nett, J. H., Hamilton, S. R., et al. (2004). Engineering of an artificial glycosylation pathway blocked in core oligosaccharide assembly in the yeast Pichia pastoris: production of complex humanized glycoproteins with terminal galactose. Glycobiology 14, 757-766. doi: $10.1093 /$ glycob/cwh104

Brown, S., Clastre, M., Courdavault, V., and O'Connor, S. E. (2015). De novo production of the plant-derived alkaloid strictosidine in yeast. Proc. Natl. Acad. Sci. U. S. A. 112, 3205-3210. doi: 10.1073/pnas.1423555112 cell factories for any heterologous production, including the new-to-nature compounds.

\section{AUTHOR CONTRIBUTIONS}

NK, SB, CG, GG, NP, and VC contributed to the writing of this manuscript. All authors contributed to the article and approved the submitted version.

\section{FUNDING}

We acknowledge funding from the ARD2020 Biopharmaceutical program of the Région Centre Val de Loire (BioPROPHARM, CatharSIS, and ETOPOCentre projects), EU Horizon 2020 research and innovation program (MIAMi projectgrant agreement $\mathrm{N}^{\circ}$ 814645), and ANR MIACYC (ANR-20-CE43-0010).
Buss, N. A. P. S., Henderson, S. J., McFarlane, M., Shenton, J. M., and De Haan, L. (2012). Monoclonal antibody therapeutics: history and future. Curr. Opin. Pharmacol. 12, 615-622. doi: 10.1016/j.coph.2012.08.001

Cardenas, G. A., and Deitcher, S. R. (2005). Risk of anaphylaxis after reexposure to intravenous lepirudin in patients with current or past heparininduced thrombocytopenia. Mayo Clin. Proc. 80, 491-493. doi: 10.4065/80. 4.491

Chen, Z., He, Y., Shi, B., and Yang, D. (2013). Human serum albumin from recombinant DNA technology: challenges and strategies. Biochim. Biophys. Acta Gen. Subj. 1830, 5515-5525. doi: 10.1016/j.bbagen.2013.04.037

Courdavault, V., O’Connor, S. E., Oudin, A., Besseau, S., and Papon, N. (2020). Towards the microbial production of plant-derived anticancer drugs. Trends Cancer 6, 444-448. doi: 10.1016/j.trecan.2020.02.004 
Cragg, G. M., and Newman, D. J. (2013). Natural products: a continuing source of novel drug leads. Biochim. Biophys. Acta 1830, 3670-3695. doi: 10.1016/j.bbagen.2013.02.008

de Ruijter, J. C., Koskela, E. V., and Frey, A. D. (2016). Enhancing antibody folding and secretion by tailoring the Saccharomyces cerevisiae endoplasmic reticulum. Microb. Cell Fact 15, 1-18. doi: 10.1186/s12934-016-0488-5

Dean, S. N., Turner, K. B., Medintz, I. L., and Walper, S. A. (2016). Targeting and delivery of therapeutic enzymes. Ther. Deliv. 8, 577-595. doi: 10.4155/tde-2017-0020

Demain, A. L., and Vaishnav, P. (2009). Production of recombinant proteins by microbes and higher organisms. Biotechnol. Adv. 27, 297-306. doi: 10.1016/j.biotechadv.2009.01.008

Duan, L., Ding, W., Liu, X., Cheng, X., Cai, J., Hua, E., et al. (2017). Biosynthesis and engineering of kaempferol in Saccharomyces cerevisiae. Microb. Cell Fact 16, 1-10. doi: 10.1186/s12934-017-0774-x

Duport, C., Spagnoli, R., Degryse, E., and Pompon, D. (1998). Self-sufficient biosynthesis of pregnenolone and progesterone in engineered yeast. Nat. Biotechnol. 16, 186-189. doi: 10.1038/nbt0298-186

Dusséaux, S., Wajn, W. T., Liu, Y., Ignea, C., and Kampranis, S. C. (2020). Transforming yeast peroxisomes into microfactories for the efficient production of high-value isoprenoids. Proc. Natl. Acad. Sci. U. S. A. 117, 31789-31799. doi: 10.1073/pnas.2013968117

Ecker, M., Deutzmann, R., Lehle, L., Mrsa, V., and Tanner, W. (2006). Pir proteins of Saccharomyces cerevisiae are attached to beta-1,3-glucan by a new protein-carbohydrate linkage. J. Biol. Chem. 281, 11523-11529. doi: 10.1074/jbc.M600314200

Eichenberger, M., Lehka, B. J., Folly, C., Fischer, D., Martens, S., Simón, E., et al. (2017). Metabolic engineering of Saccharomyces cerevisiae for de novo production of dihydrochalcones with known antioxidant, antidiabetic, and sweet tasting properties. Metab. Eng. 39, 80-89. doi: 10.1016/j.ymben.2016.10.019

Galanie, S., Thodey, K., Trenchard, I. J., Filsinger Interrante, M., and Smolke, C. D. (2015). Complete biosynthesis of opioids in yeast. Science 349, 1095-1100. doi: $10.1126 /$ science.aac9373

Gao, T., Ren, Y., Li, S., Lu, X., and Lei, H. (2021). Immune response induced by oral administration with a Saccharomyces cerevisiae-based SARS-CoV2 vaccine in mice. Microb. Cell Fact. 20, 1-10. doi: 10.1186/s12934-021-0 1584-5

Gasmi, N., Ayed, A., Ammar, B. B. H., Zrigui, R., Nicaud, J. M., and Kallel, H. (2011). Development of a cultivation process for the enhancement of human interferon alpha $2 \mathrm{~b}$ production in the oleaginous yeast, Yarrowia lipolytica. Microb. Cell Fact. 10, 1-11. doi: 10.1186/1475-2859-10-90

Greinacher, A., Lubenow, N., and Eichler, P. (2003). Anaphylactic and anaphylactoid reactions associated with lepirudin in patients with heparin-induced thrombocytopenia. Circulation 108, 2062-2065. doi: 10.1161/01.CIR.0000096056.37269.14

Grewal, P. S., Samson, J. A., Baker, J. J., Choi, B., and Dueber, J. E. (2021). Peroxisome compartmentalization of a toxic enzyme improves alkaloid production. Nat. Chem. Biol. 17, 96-103. doi: 10.1038/s41589-020-00668-4

Guirimand, G., Kulagina, N., Papon, N., Hasunuma, T., and Courdavault, V. (2020). Innovative tools and strategies for optimizing yeast cell factories. Trends Biotechnol. 39, 488-504. doi: 10.1016/j.tibtech.2020.08.010

Ho, W., Gao, M., Li, F., Li, Z., Zhang, X. Q., and Xu, X. (2021). Next-generation vaccines: nanoparticle-mediated DNA and mRNA delivery. Adv. Healthc. Mater. 10, 1-17. doi: 10.1002/adhm.202001812

Huang, M., Wang, J., Qin, J., Petranovic, D., and Nielsen, J. (2018). Engineering the protein secretory pathway of Saccharomyces cerevisiae enables improved protein production. PNAS 115, E11025-E11032. doi: 10.1073/pnas.18099 21115

Ishchuk, O. P., Frost, A. T., Muñiz-Paredes, F., Matsumoto, S., Laforge, N., Eriksson, N. L., et al. (2021). Improved production of human hemoglobin in yeast by engineering hemoglobin degradation. Metab. Eng. 66, 259-267. doi: 10.1016/j.ymben.2021.05.002

Jung, S. T., and Kim, D. Il. (2017). Mass production of full-length IgG monoclonal antibodies from mammalian, yeast, and bacterial hosts. Emerg. Areas Bioeng. 679-695. doi: 10.1002/9783527803293.ch39

Kaplon, H., and Reichert, J. M. (2019). Antibodies to watch in 2019. MAbs 11, 219-238. doi: 10.1080/19420862.2018.1556465
Kim, H. J., and Kim, H. J. (2017). Yeast as an expression system for producing virus-like particles: what factors do we need to consider? Lett. Appl. Microbiol. 64, 111-123. doi: 10.1111/lam.12695

Korte, W. (2014). Catridecacog: a breakthrough in the treatment of congenital factor XIII A-subunit deficiency? J. Blood Med. 5:107. doi: 10.2147/JBM.S35395

Kumar, R., and Kumar, P. (2019). Yeast-based vaccines: new perspective in vaccine development and application. FEMS Yeast Res. 19, 1-22. doi: 10.1093/femsyr/foz007

Laukens, B., De Visscher, C., and Callewaert, N. (2015). Engineering yeast for producing human glycoproteins: where are we now? Future Microbiol. 10, 21-34. doi: 10.2217/fmb.14.104

Lee, J. W., Na, D., Park, J. M., Lee, J., Choi, S., and Lee, S. Y. (2012). Systems metabolic engineering of microorganisms for natural and non-natural chemicals. Nat. Chem. Biol. 8, 536-546. doi: 10.1038/nchembio.970

Lehka, B. J., Eichenberger, M., Bjørn-Yoshimoto, W. E., Vanegas, K. G., Buijs, N., Jensen, N. B., et al. (2017). Improving heterologous production of phenylpropanoids in Saccharomyces cerevisiae by tackling an unwanted side reaction of Tsc13, an endogenous double-bond reductase. FEMS Yeast Res. 17:fox004. doi: 10.1093/femsyr/fox004

Lei, H., Xie, B., Gao, T., Cen, Q., and Ren, Y. (2020). Yeast display platform technology to prepare oral vaccine against lethal H7N9 virus challenge in mice. Microb. Cell Fact. 19, 1-9. doi: 10.1186/s12934-020-01316-1

Li, H., Sethuraman, N., Stadheim, T. A., Zha, D., Prinz, B., Ballew, N., et al. (2006). Optimization of humanized IgGs in glycoengineered Pichia pastoris. Nat. Biotechnol. 24, 210-215. doi: 10.1038/nbt1178

Li, H., Wang, Y., Xu, A., Li, S., Jin, S., and Wu, D. (2011). Large-scale production, purification and bioactivity assay of recombinant human interleukin-6 in the methylotrophic yeast Pichia pastoris. FEMS Yeast Res. 11, 160-167. doi: 10.1111/j.1567-1364.2010.00701.x

Li, M., Schneider, K., Kristensen, M., Borodina, I., and Nielsen, J. (2016). Engineering yeast for high-level production of stilbenoid antioxidants. Sci. Rep. 6, 1-8. doi: 10.1038/srep36827

Li, Y., Li, S., Thodey, K., Trenchard, I., Cravens, A., and Smolke, C. D. (2018). Complete biosynthesis of noscapine and halogenated alkaloids in yeast. Proc. Natl. Acad. Sci. U. S. A. 115, E3922-E3931. doi: 10.1073/pnas.1721469115

Lipiäinen, T., Peltoniemi, M., Sarkhel, S., Yrjönen, T., Vuorela, H., Urtti, A., et al. (2015). Formulation and stability of cytokine therapeutics. J. Pharm. Sci. 104, 307-326. doi: 10.1002/jps.24243

Liu, H., Fan, J., Wang, C., Li, C., and Zhou, X. (2019). Enhanced $\beta$ Amyrin Synthesis in Saccharomyces cerevisiae by coupling an optimal acetyl-CoA supply pathway. J. Agric. Food Chem. 67, 3723-3732. doi: 10.1021/acs.jafc.9b00653

Liu, L., Martínez, J. L., Liu, Z., Petranovic, D., and Nielsen, J. (2014). Balanced globin protein expression and heme biosynthesis improve production of human hemoglobin in Saccharomyces cerevisiae. Metab. Eng. 21, 9-16. doi: 10.1016/j.ymben.2013.10.010

Liu, X., Cheng, J., Zhang, G., Ding, W., Duan, L., Yang, J., et al. (2018). Engineering yeast for the production of breviscapine by genomic analysis and synthetic biology approaches. Nat. Commun. 9:448. doi: 10.1038/s41467-018-02883-Z

Luo, X., Reiter, M. A., d'Espaux, L., Wong, J., Denby, C. M., Lechner, A., et al. (2019). Complete biosynthesis of cannabinoids and their unnatural analogues in yeast. Nature 567, 123-126. doi: 10.1038/s41586-019-0978-9

Mallu, M. R., Vemula, S., and Ronda, S. R. (2016). Production, purification and characterization of recombinant human antithrombin III by Saccharomyces cerevisiae. Electron. J. Biotechnol. 22, 81-89. doi: 10.1016/j.ejbt.2016.06.002

Martínez, J. L., Liu, L., Petranovic, D., and Nielsen, J. (2012). Pharmaceutical protein production by yeast: towards production of human blood proteins by microbial fermentation. Curr. Opin. Biotechnol. 23, 965-971. doi: 10.1016/j.copbio.2012.03.011

Martínez, J. L., Liu, L., Petranovic, D., and Nielsen, J. (2015). Engineering the oxygen sensing regulation results in an enhanced recombinant human hemoglobin production by Saccharomyces cerevisiae. Biotechnol. Bioeng. 112, 181-188. doi: 10.1002/bit.25347

Metcalf, D. (2010). The colony-stimulating factors and cancer. Nat. Rev. Cancer 10, 425-434. doi: $10.1038 / \mathrm{nrc} 2843$

Mohsen, M. O., Zha, L., Cabral-Miranda, G., and Bachmann, M. F. (2017). Major findings and recent advances in virus-like particle (VLP)-based vaccines. Semin. Immunol. 34, 123-132. doi: 10.1016/j.smim.2017.08.014 
Nowrouzi, B., Li, R. A., Walls, L. E., d'Espaux, L., Malc, K., Liang, L., et al. (2020). Enhanced production of taxadiene in Saccharomyces cerevisiae. Microb. Cell Fact. 19, 1-12. doi: 10.1186/s12934-020-01458-2

Orvieto, R., and Seifer, D. B. (2016). Biosimilar FSH preparations- are they identical twins or just siblings? Reprod. Biol. Endocrinol. 14, 10-15. doi: 10.1186/s12958-016-0167-8

Paddon, C. J., Westfall, P. J., Pitera, D. J., Benjamin, K., Fisher, K., McPhee, D., et al. (2013). High-level semi-synthetic production of the potent antimalarial artemisinin. Nature 496, 528-532. doi: 10.1038/nature12051

Petros, S. (2008). Lepirudin in the management of patients with heparin-induced thrombocytopenia. Biol. Targets Ther. 2, 481-490. doi: 10.2147/BTT.S3415

Pittet, M., and Conzelmann, A. (2006). Biosynthesis and function of GPI proteins in the yeast Saccharomyces cerevisiae. Biochim Biophys Acta. 1771, 405-420. doi: 10.1016/j.bbalip.2006.05.015

Pollard, A. J., and Bijker, E. M. (2021). A guide to vaccinology: from basic principles to new developments. Nat. Rev. Immunol. 21, 83-100. doi: 10.1038/s41577-020-00479-7

Potgieter, T. I., Cukan, M., Drummond, J. E., Houston-Cummings, N. R., Jiang, Y., Li, F., et al. (2009). Production of monoclonal antibodies by glycoengineered Pichia pastoris. J. Biotechnol. 139, 318-325. doi: 10.1016/j.jbiotec.2008. 12.015

Pyne, M. E., Kevvai, K., Grewal, P. S., Narcross, L., Choi, B., Bourgeois, L., et al. (2020). A yeast platform for high-level synthesis of tetrahydroisoquinoline alkaloids. Nat. Commun. 11, 1-10. doi: 10.1038/s41467-020-17172-x

Pyne, M. E., Narcross, L., and Martin, V. J. J. (2019). Engineering plant secondary metabolism in microbial systems. Plant Physiol. 179, 844-861. doi: 10.1104/pp.18.01291

Rodriguez, A., Strucko, T., Stahlhut, S. G., Kristensen, M., Svenssen, D. K., Forster, J., et al. (2017). Metabolic engineering of yeast for fermentative production of flavonoids. Bioresour. Technol. 245, 1645-1654. doi: 10.1016/j.biortech.2017.06.043

Roohvand, F., Shokri, M., Abdollahpour-Alitappeh, M., and Ehsani, P. (2017). Biomedical applications of yeast- a patent view, part one: yeasts as workhorses for the production of therapeutics and vaccines. Expert Opin. Ther. Pat. 27, 929-951. doi: 10.1080/13543776.2017.1339789

Srinivasan, P., and Smolke, C. D. (2019). Engineering a microbial biosynthesis platform for de novo production of tropane alkaloids. Nat. Commun. 10, 1-15. doi: 10.1038/s41467-019-11588-w

Srinivasan, P., and Smolke, C. D. (2020). Biosynthesis of medicinal tropane alkaloids in yeast. Nature 585, 614-619. doi: 10.1038/s41586-020-2650-9

Szczebara, F. M., Chandelier, C., Villeret, C., Masurel, A., Bourot, S., Duport, C., et al. (2003). Total biosynthesis of hydrocortisone from a simple carbon source in yeast. Nat. Biotechnol. 21, 143-149. doi: 10.1038/nbt775

Taipa, A. M., Fernandes, P., and de Carvalho, C. C. C. R. (2019). "Therapeutic enzymes: function and clinical implications," in Production and purification of therapeutic enzymes, ed N. Labrou (Singapore: Springer), 1-19. doi: 10.1007/978-981-13-7709-9_1

Trantas, E., Panopoulos, N., and Ververidis, F. (2009). Metabolic engineering of the complete pathway leading to heterologous biosynthesis of various flavonoids and stilbenoids in Saccharomyces cerevisiae. Metab. Eng. 11, 355-366. doi: 10.1016/j.ymben.2009.07.004

Tripathi, N. K., and Shrivastava, A. (2019). Recent developments in bioprocessing of recombinant proteins: expression hosts and process development. Front. Bioeng. Biotechnol. 7:420. doi: 10.3389/fbioe.2019.00420
Walsh, G. (2010). Biopharmaceutical benchmarks 2010. Nat. Biotechnol. 28, 917-924. doi: 10.1038/nbt0910-917

Walsh, G. (2018). Biopharmaceutical benchmarks 2018. Nat. Biotechnol. 36, 1136-1145. doi: 10.1038/nbt.4305

Wang, G., Huang, M., and Nielsen, J. (2017). Exploring the potential of Saccharomyces cerevisiae for biopharmaceutical protein production. Curr. Opin. Biotechnol. 48, 77-84. doi: 10.1016/j.copbio.2017.03.017

Westfall, P. J., Pitera, D. J., Lenihan, J. R., Eng, D., Woolard, F. X., Regentin, R., et al. (2012). Production of amorphadiene in yeast, and its conversion to dihydroartemisinic acid, precursor to the antimalarial agent artemisinin. Proc. Natl. Acad. Sci. U. S. A. 109, 111-118. doi: 10.1073/pnas.11107 40109

Wong, J., de Rond, T., d'Espaux, L., van der Horst, C., Dev, I., Rios-Solis, L., et al. (2018). High-titer production of lathyrane diterpenoids from sugar by engineered Saccharomyces cerevisiae. Metab. Eng. 45, 142-148. doi: 10.1016/j.ymben.2017.12.007

Yang, H., Li, J., Du, G., and Liu, L. (2017). Microbial production and molecular engineering of industrial enzymes: challenges and strategies. Amsterdam: Elsevier Inc. doi: 10.1016/B978-0-12-803725-6.00006-6

Yang, X., Tang, H., Song, M., Shen, Y., Hou, J., and Bao, X. (2019). Development of novel surface display platforms for anchoring heterologous proteins in Saccharomyces cerevisiae. Microb. Cell Fact. 18:85. doi: 10.1186/s12934-019-1133-x

Zhang, C., Liu, J., Zhao, F., Lu, C., Zhao, G. R., and Lu, W. (2018). Production of sesquiterpenoid zerumbone from metabolic engineered Saccharomyces cerevisiae. Metab. Eng. 49, 28-35. doi: 10.1016/j.ymben.2018. 07.010

Zhang, J., Petersen, S. D., Radivojevic, T., Ramirez, A., Pérez-Manríquez, A., Abeliuk, E., et al. (2020). Combining mechanistic and machine learning models for predictive engineering and optimization of tryptophan metabolism. Nat. Commun. 11:4880. doi: 10.1038/s41467-020-17910-1

Zhuang, Y., Yang, G. Y., Chen, X., Liu, Q., Zhang, X., Deng, Z., et al. (2017). Biosynthesis of plant-derived ginsenoside Rh2 in yeast via repurposing a key promiscuous microbial enzyme. Metab. Eng. 42, 25-32. doi: 10.1016/j.ymben.2017.04.009

Conflict of Interest: The authors declare that the research was conducted in the absence of any commercial or financial relationships that could be construed as a potential conflict of interest.

Publisher's Note: All claims expressed in this article are solely those of the authors and do not necessarily represent those of their affiliated organizations, or those of the publisher, the editors and the reviewers. Any product that may be evaluated in this article, or claim that may be made by its manufacturer, is not guaranteed or endorsed by the publisher.

Copyright (C) 2021 Kulagina, Besseau, Godon, Goldman, Papon and Courdavault. This is an open-access article distributed under the terms of the Creative Commons Attribution License (CC BY). The use, distribution or reproduction in other forums is permitted, provided the original author(s) and the copyright owner(s) are credited and that the original publication in this journal is cited, in accordance with accepted academic practice. No use, distribution or reproduction is permitted which does not comply with these terms. 